\title{
Acquired Hemophilia in a Patient With Rheumatoid Arthritis: Case Report and Literature Review
}

\begin{abstract}
Acquired hemophilia $(A H)$ is a rare bleeding disorder caused by the spontaneous development of autoantibodies against coagulation factors, most commonly factor ( $F$ ) VIII (acquired hemophilia A, AHA). The clinical manifestation of AHA includes mostly spontaneous hemorrhages into skin, mucous membranes, muscles, soft tissues, or joints. AHA should be suspected when a patient with no history of hemorrhages presents with bleeding and an unexplained prolonged activated partial thromboplastin time. The diagnosis is based on the clinical picture, the presence of low FVIII activity and evidence of FVIII inbibitor. In around half of patients, an underlying disorder (rheumatic diseases, malignancy, infections) or taking some drugs are associated with AHA; the remaining cases are idiopathic. Rheumatoid arthritis is a chronic inflammatory condition, marked by swelling and tenderness of small joints; it is usually treated with steroid and immunosuppressive drugs such as methotrexate, TNF-alpha inhibitors, and other biologic therapies (abatacept, tocilizumab, rituximab).

We presented a patient with rheumatoid arthritis who developed acquired hemophilia $A$ with hemarthroses; starting from this case, we focused on the literature about AHA in rheumatic diseases. We found 35 cases, 15 in systemic lupus erythematosus and 12 in rheumatoid arthritis, while the remaining cases were reported in Sjögren's syndrome, polymyalgia rheumatica, systemic sclerosis, and psoriatic arthritis. Ecchymosis and cutaneous hematomas were the main clinical features while hemarthroses was quite a rare condition, shown in just three patients.
\end{abstract}

Keywords: Acquired Hemophilia; Arthritis, Rheumatoid; Rheumatic Diseases

Emofilia acquisita in un paziente con artrite reumatoide: caso clinico e revisione della letteratura

CMI 2018; 12(1): 53-61

bttps://doi.org/10.7175/cmi.v12i1.1362

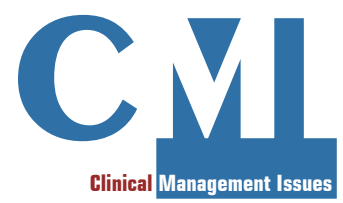

Case Report
${ }^{1}$ Department of

Rheumatology, University

of Verona, Italy

${ }^{2}$ Department of

Rheumatology, S. Chiara

Hospital, Trento, Italy

3 Department of

Hematology, S. Chiara

Hospital, Trento, Italy

${ }^{4}$ Operative Unit

of Rheumatology,

Department of Medicine,

University of Padova, Italy

\section{INTRODUCTION}

Acquired hemophilia (AH) is an autoimmune disease caused by the formation of inhibitory autoantibodies against coagulation factors.

These inhibitory autoantibodies (immunoglobulin $\mathrm{IgG}$ ) neutralize the activation or function or accelerate the clearance of a specific clotting factor [1], mainly FVIII (acquired hemophilia A-AHA), although all the coagulation factors can be involved.

\section{Why Do we Describe This Case}

$A H$ is an underdiagnosed and misdiagnosed disease in the daily clinical practice. It is important to suspect AH in a rheumatic patient with spontaneous hemorrhages with no apparent cause. Due to its potential fatal outcome, AH should promptly be recognized in order to control the hemorrhagic events and eradicate the clotting inhibitor with a strong immunosuppressive treatment
Corresponding author Masen Abdel Jaber masenaj@gmail.com 
AHA is a rare but challenging picture due to the frequent delayed diagnosis or inadequate treatment, which contribute to a high mortality rate.

Data from three large cohorts from Australia, South Wales, and UK described an incidence between 1.20 and 1.48 cases per million/year [2-5]. AHA predominantly affects the elderly, but can also be found in younger patients in pregnancy and rheumatic/autoimmune diseases. About half of cases are idiopathic, while the other half is secondary to other conditions: malignancy, autoimmune diseases, pregnancy, medications, infections [6].

The etiology is probably multifactorial: genetic and environmental factors interact in order to cause a loss of the immune tolerance and the formation of the inhibitory antibodies [2].

These ones cause a rapid inactivation of FVIII followed by a slow phase and usually they do not completely inactivate it, in contrast with the congenital form of hemophilia, in which alloantibodies inhibit FVIII in linear proportion to their concentration and in a complete manner. Consequently, the antibody and measurable levels of FVIII in AHA may be found simultaneously in circulation. Moreover, there is just a slight correlation between FVIII level and bleeding severity [2], thus FVIII level cannot be used to identify patients at higher risk.

The diagnosis of AHA is hard and should be made by a Hematological Division with experience in the setting of coagulation disorders. Main features supporting its formulation are spontaneous bleeding events and laboratory investigations pointing to a coagulation disorder.

AHA should be suspected in every patient with abnormal or spontaneous bleeding and coagulation abnormalities, such as prolongation of activated partial thromboplastin time (APTT) with normal prothrombin time (PT) and normal platelet count. AHA can also present just with an isolated prolonged APTT without bleeding events.

A relevant feature of AHA is the difference in the bleeding pattern compared with the congenital form. Bleeding frequently start spontaneously but some episodes can even occur after trauma or surgery. Many potential sites may be involved: subcutaneous or mucosal bleeding [4] are the most common manifestations, followed by muscle bleeding and bleeding in other sites (genitourinary, gastrointestinal tract, retroperitone- al, intracranial) [7]. Hemarthroses are quite rare, in contrast to the congenital form [4].

Diagnosis should be confirmed by laboratory investigation: the initial step is based on the demonstration of an elevated APTT, not corrected by a mixing study (i.e. incubation of patient plasma with pooled normal plas$\mathrm{ma}(1: 1)$ for $1-2 \mathrm{~h}$ at $\left.37^{\circ} \mathrm{C}\right)$ [8]. The second step is the demonstration of reduced FVIII activity and evidence of a FVIII inhibitor, estimated with the Bethesda assay [1]. In AHA, FIX and FXI levels can be normal. As underlined by the most recent guidelines presented by the United Kingdom Haemophilia Centre Doctors' Organization (UKHCDO), it is also important to exclude heparin treatment measuring thrombin time (TT) [9].

Data from a large European registry including 501 patients (European Acquired Haemophilia Registry, EACH2) [10] showed an inverse correlation between the inhibitor titer and the residual FVIII activity. Patients who had a bleeding event had a significant lower FVIII activity and higher inhibitor titers at presentation than patient who were diagnosed by abnormal APTT on routine blood test $[2,10]$. The inhibitor titer or residual FVIII activity are not directly related to the severity of bleeding symptoms or mortality; consequently, the clinician cannot use them as predicting factor, but the titers are common measure to monitor the eradication therapy efficacy $[2,10]$.

Treatment consists on bleeding control on the one hand and on the antibody eradication on the other hand.

It is recommended to immediately start antihemorrhagic treatment in patients with active bleeding symptoms, although small bleeding do not require intervention.

The most common treatment are recombinant factor VII (rFVII) and activated prothrombin complex concentrate (aPCC) [2], which demonstrate an efficacy rate of about 90\% [11-13].

The eradication of the inhibitory antibodies is mandatory, independently by the clinical picture severity and is achieved with the use of a strong immunosuppressive treatment.

Corticosteroids (prednisone $1 \mathrm{mg} / \mathrm{kg}$ daily), in association with cyclophosphamide or rituximab are the main therapeutic option [6]. Data from the $\mathrm{EACH} 2$ registry showed better results in the steroid-cyclophosphamide group than in the steroid-rituximab or in the steroid groups [14]. Therapy should anyway be individualized considering con- 


\begin{tabular}{|c|c|c|c|c|}
\hline & $\begin{array}{l}\text { 06/26/2017 } \\
\text { (diagnosis) }\end{array}$ & $07 / 05 / 2017$ & 08/18/2017 & 09/01/2017 \\
\hline $\mathrm{Hb}(\mathrm{g} / \mathrm{dl})$ & 9.5 & 10.9 & 13.8 & 13.5 \\
\hline PT (ratio) & 1.05 & 0.98 & 0.90 & 0.95 \\
\hline APTT (ratio) & 2.49 & 2.35 & 1.01 & 0.89 \\
\hline FVIII (\%) & 1 & 6 & 63 & 113 \\
\hline FVIII Ab (BU/ml) & २2 & NA & 1 & Absent \\
\hline
\end{tabular}

Table I. Laboratory parameters during therapy.

APTT $=$ activated partial thromboplastin time;

$\mathrm{BU}=$ Bethesda unit;

FVIII = factor VIII activity;

FVIII $\mathrm{Ab}=$ factor VIII

inhibitory antibodies;

$\mathrm{Hb}=$ hemoglobin level;

$\mathrm{NA}=$ not available;

$\mathrm{PT}=$ prothrombin time

comitant disease, general condition and prognostic factors (high inhibitor title).

The FVIII activity usually restores in 5 weeks or more but patients with FVIII activity $<1 \%$ at baseline require longer time compared with other patients [6].

Prognosis can be severe due to the fatal bleeding rate, especially those with intracranial or gastrointestinal manifestations. Overall mortality has been estimated in a range between $7.9 \%$ and $33 \%$ [5,15-17]: age, malignancy and lower hemoglobin levels are poor risk factors [2].

\section{CASE REPORT}

A 76-year-old woman affected by longstanding seropositive rheumatoid arthritis (RA) experienced persistent clinical remission for many years with a combination therapy made by hydroxychloroquine (HCQ, $200 \mathrm{mg} /$ day) and low dose steroid (methylprednisolone, $4 \mathrm{mg} /$ day).

On June 2017, the patient consulted the emergency department (ED) for the development of acute left knee swelling: the arthrocentesis made by a rheumatologist revealed a clear hematic synovial fluid and the $\mathrm{X}$-ray examination excluded any fracture. No history of trauma were reported and no antiplatelet or anticoagulant medications were ever taken.

The patient came back to the ED just few days later, showing large and multiple ecchymosis on both arms and legs, on the abdomen and on both breasts. A Doppler ultrasound revealed a muscular hematoma on the left thigh and preliminary blood tests showed an abnormal APTT (2.03 ratio, normal values $0.80-1.20$ ), thus she was hospitalized into the Hematological Unit for further investigations.

Laboratory tests were as follows: white blood cell count $10.3 \times 10^{\%} / 1$, hemoglobin level $9.5 \mathrm{~g} / \mathrm{dl}$, platelets $241 \times 10^{9} / 1$, C-reactive protein $73 \mathrm{mg} / 1$. Renal function was normal: creatinine $0.8 \mathrm{mg} / \mathrm{dl}$. The blood coagulation study confirmed the elevated APTT (2.49 ratio) with normal PT (1.05 ratio), while further laboratory studies highlighted a low FVIII activity (1\%, normal values 50-150) and the presence of an FVIII inhibitor (22 Bethesda units/ml, normal values $<0.5)$. These data suggested the diagnosis of acquired hemophilia $\mathrm{A}$.

The blood coagulation study confirmed the elevated APTT with normal PT, while further laboratory studies highlighted a low FVIII activity and the presence of an FVIII inhibitor. These data suggested the diagnosis of acquired hemophilia A.

CT total body excluded malignant forms. The patient immediately started oral prednisone $(1 \mathrm{mg} / \mathrm{kg}, 75 \mathrm{mg} / \mathrm{day})$ and then rituximab few days later $\left(375 \mathrm{mg} / \mathrm{m}^{2}, 4\right.$ weekly infusions). During the next weeks the ecchymosis and the muscular hematoma slowly regressed and blood tests gradually improved: after one month of steroid and rituximab therapy, hemoglobin level rose to $11.5 \mathrm{~g} / \mathrm{dl}$, while APTT was still abnormal (2.11 ratio), turning back to a normal value after another month of steroids. At that time FVIII activity was $63 \%$ and FVIII inhibitor antibody title was $1 \mathrm{BU} / \mathrm{ml}$, becoming undetectable few weeks later (Table I).

Prednisone was slowly reduced during the following months while rituximab was not repeated considering the clinical and laboratory improving picture. At the time of the writing (May 2018) the patient is taking just $5 \mathrm{mg}$ prednisone for the chronic treatment of rheumatoid arthritis and no new hemorrhagic events are reported; hemoglobin level and blood coagulation tests are normal.

\section{DISCUSSION}

As mentioned above, acquired hemophilia can occur in a patient with an underlying rheumatic disorder. Other potential causes are: malignancy, pregnancy, infections or 


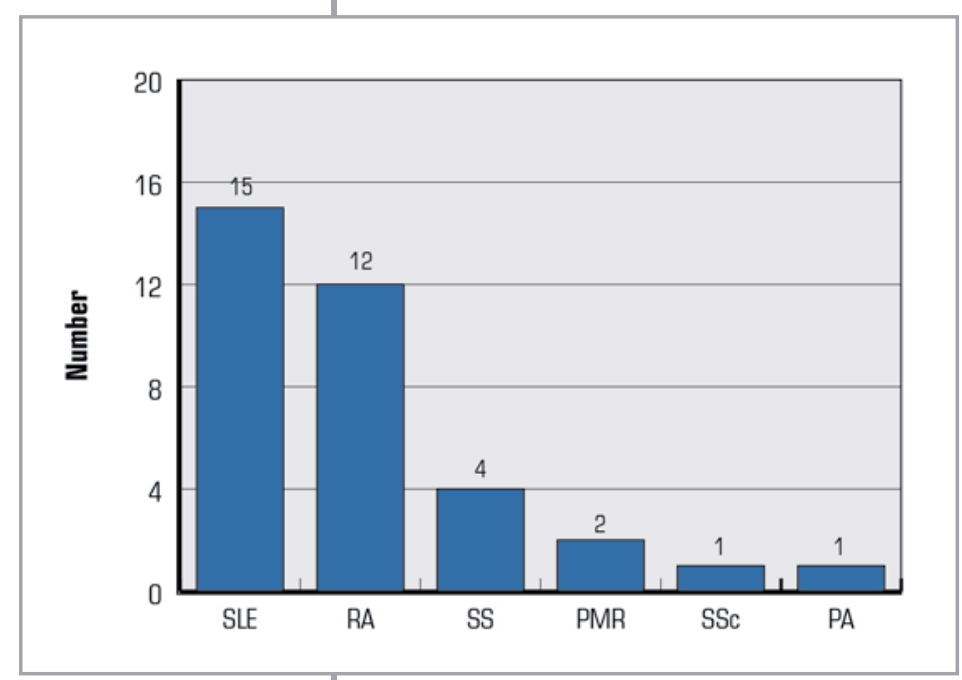

Figure 1. Reported acquired hemophilia cases in rheumatic diseases.

$\mathrm{PA}=$ Psoriatic Arthritis PMR = Polymyalgia Rheumatica;

$\mathrm{RA}=$ Rheumatoid

Arthritis; SLE $=$ Systemic Lupus Erythematosus; $\mathrm{SS}=$ Sjogren's Syndrome; $\mathrm{SSc}=$ Systemic Sclerosis idiopathic forms, which accounts for about half of cases. Using PubMed database, we searched for acquired hemophilia case reports in rheumatic diseases.

We found 35 cases (Figure 1): 15 in systemic lupus erythematosus (SLE) [18-32], 12 in rheumatoid arthritis [28,33-43], 4 in Sjögren's syndrome (SS) [44-47], 2 in polymyalgia rheumatica (PMR) [48,49], 1 in systemic sclerosis $(\mathrm{SSc})$ [50], and 1 in psoriatic arthritis (PA) [51].

Among the 34 publications found (1 publication presented 2 case reports, one in RA and one in SLE):

- 19 were full text available;

- 3 were not full text but abstract available and with sufficient laboratory and clinical data about the case;

- 12 were not full text or abstract available or the abstract was without sufficient laboratory and clinical data about the case.

Among the 23 patients' records available, 18 were women and 5 were men. Mean age was 52.9 years. A higher mean age was evident in RA group than the SLE one, a detection quite predictable considering the natural course of the two diseases.

Factor VIII inhibitor antibodies were present in all cases while factor IX antibodies just in three cases $[21,23,44]$.

The main clinical presentation was ecchymosis/cutaneous hematomas, (19 of $23,82 \%)[19-22,24,25,28,29,35-$ $38,40,44,45,48,50,51]$ followed by muscular hematomas (10 of $23,43 \%$ ) [22,23,28,3 $6,37,39,40,44,49,51]$, the latters mainly in the RA group (Table II). As expected, hemarthroses were quite rare in the literature, described in just two cases, one in RA and another one in SLE $[23,40]$. These clinical results reflect other data reported in the literature, first those showed by Knoebl et al. in the $\mathrm{EACH} 2$ registry, except for a higher rate of cutaneous involvement ( $82 \%$ versus 53\%) [10].

All the hemorrhagic events were spontaneous, with no history of relevant trauma. One patient with SLE experienced intraperitoneal massive hemorrhage due to gallbladder rupture with consequent multiple organ failure and death [30]. Another woman died for massive abdominal wall hemorrhage [37].

RA patients showed disease remission at the time of the hematological diagnosis except for one [39]; two patients were on biological therapy with TNF-alpha inhibitors at the time of the AHA discovery [36,37].

In the SLE group, the connectivity diagnosis was concomitant with the $\mathrm{AH}$ one in 5 patients [19-22,29], suggesting a potential role of the disease activity on the inhibitory FVIII antibodies formation. The only systemic sclerosis patient developed $\mathrm{AH}$ after autologous hematopoietic stem cell transplantation [50]. A case of AH in SLE during pregnancy was reported [2].

Treatment of AH consists of two essential ways: control of bleeding and elimination of the inhibitor.

In our literature review, 11 patients required antihemorrhagic treatment, which consisted in: factor VIII concentrates, recombinant factor VIIa, FIX plasma concentrate, factor eight inhibitor bypassing activity (FEIBA), or activated prothrombin complex concentrates (aPCC) [20,21,23,25,29,30,35, $37,38,40,50]$.

To eliminate or suppress the activity of the FVIII inhibitor, steroid therapy was the first and essential step, since all patients took it. Oral route was the preferred one.

A variety of immunosuppressive drugs were used in association, proving that many cases don't respond to steroid as monotherapy, especially when inhibitory titers are high. Only one patient reached disease regression with just steroids [20].

Cyclophosphamide was the main immunosuppressant reported, since its administration was observed in 15 patients $[20,22-25,28,35-38,40,48,49,51]$ as firstline treatment or after failure of other immunosuppressive drugs, showing to be effective in 11 of them. Rituximab was another choice, mainly as weekly infusion, as in our case. Six cases reported its use, 3 of them as 


\begin{tabular}{|c|c|c|c|c|c|c|c|c|c|}
\hline & Reference & Age/sex & $\begin{array}{c}\text { Hemorrhagic } \\
\text { feature }\end{array}$ & APTT (s) & FVIII $(\%)$ & $\begin{array}{l}\text { FUIII in. } \\
\text { (BU/ml) }\end{array}$ & $\begin{array}{l}\text { Hemorrhagic } \\
\text { treatment }\end{array}$ & CS & IS \\
\hline 1 & 34 & $48 / F$ & 1 & 112 & 5.4 & 29.9 & Yes & Yes & CyC $>$ RTX \\
\hline 2 & 35 & $47 / F$ & 1,3 & 84 & 1 & 45 & No & Yes & CyC $>$ AZA \\
\hline 3 & 36 & 78/F & 1,3 & 56 & 3 & २2 & Yes & Yes & СуС \\
\hline 4 & 37 & 78/M & 1 & 115 & 1 & 839 & Yes & Yes & СуС \\
\hline 5 & 38 & $61 / F$ & 3 & 61 & NA & 2 & No & NA & RTX \\
\hline 6 & 39 & $71 / \mathrm{F}$ & $1,2,3$ & 86 & 1 & 28 & Yes & Yes & IVIG + CyC \\
\hline 7 & 27 & $54 / F$ & 1,3 & 91 & 1 & 145.6 & No & Yes & CyC \\
\hline 8 & Current case & 76/F & $1,2,3$ & 83 & 1 & 22 & No & Yes & RTX \\
\hline
\end{tabular}

second choice therapy $[20,35,39,45,48,50]$; in all those reports, treatment ended with eradication of the inhibitory antibodies and disease control.

Alternative immunosuppressive drugs were cyclosporine $[29,30]$ and azathioprine $[19,36,44]$, while intravenous immunoglobulin were used in association with cyclophosphamide or azathioprine in two patients and as monotherapy in just one, showing however no efficacy $[23,40,44]$.

Table II shows the main characteristics of available papers concerning acquired hemophilia cases with rheumatoid arthritis.

Rituximab is a humanized chimeric antiCD20 monoclonal antibody initially used for the treatment of some hematological malignancies, mainly lymphomas. Thanks to its specific anti-B cells activity, it is also used in a variety of autoimmune disorders, even rheumatic ones, such as rheumatoid arthritis, granulomatosis polyangiitis, and microscopic polyangiitis.

We chose rituximab in order to use a drug that could be helpful to tackle both $\mathrm{AH}$ and
$\mathrm{RA}$, since it is indicated in the treatment of RA [52]. Although both rituximab and cyclophosphamide can induce an immunosuppression condition with a higher infection risk, the rituximab choice was also supported by the patient's fear about bladder complications with cyclophosphamide. In the rheumatological setting, rituximab is usually administered on two different infusions 2 weeks apart $(1000 \mathrm{mg} \times 2)$, repeated after 6 months. A monthly scheme was preferred in our patient, since the hematological condition imposed a more aggressive treatment than those used in RA. Rituximab therapy is also reported in other cases of $\mathrm{AH}$ not related to autoimmune diseases [53-63].

\section{CONCLUSION}

We described a case of acquired hemophilia $\mathrm{A}$ in a patient with long-standing rheumatoid arthritis, treated with steroids and rituximab with excellent response. The use of immunosuppressive drugs in associa-
Table II. A review of reported acquired hemophilia cases with rheumatoid arthritis.

Hemorrhagic features: $1=$ cutaneous hematoma/ ecchymosis

2 = hemarthroses;

$3=$ muscular hematoma

Hemorrhagic treatments were: factor VIII

concentrates, recombinan

factor VIIa, FIX plasma concentrate, factor eight inhibitor bypassing activity (FEIBA), and activated prothrombin complex concentrates (aPCC).

$>$ = switch;

APTT $=$ activated partial

thromboplastin time;

$\mathrm{AZA}=$ azathioprine;

$\mathrm{BU}=$ Bethesda unit;

$\mathrm{CS}=$ corticosteroid therapy;

$\mathrm{CyC}=$ cyclophosphamide,

$\mathrm{F}=$ female; FVIII = factor

VIII activity; FVIII

in. = FVIII inhibitor;

IS = immunosuppressive drug; IVIG = intravenous immunoglobulin; $\mathrm{M}=$ male;

$\mathrm{NA}=$ not available;

RTX = rituximab

\section{Keypoints}

- AH is a potentially fatal condition marked by spontaneous bleeding, mainly ecchymosis, mucosal bleeding, and muscular hematomas

- AH can be idiopathic or associated to an underlying condition such as malignancy, autoimmune disease or pregnancy

- AH develops after the formation of inhibitory antibodies against one or more clotting factor, mainly factor VIII

- Laboratory investigations are mandatory to confirm the diagnosis: rise in APTT, reduced FVIII activity, presence of a FVIII inbibitor

- The therapeutic approach relies on immunosuppressive drugs, mostly high dose steroids associated with cyclophosphamide or rituximab. Use of antihemorrhagic treatment relies on the clinical condition and on the bleeding's severity

- Many rheumatic patients developing AH are described in the literature database, especially $S L E$ and $R A$ patients. We described a case of $A H A$ in a woman with long-standing $R A$, treated with steroid and rituximab followed by an excellent outcome. 
tion with steroids is largely diffuse. Thanks to our clinical case description, we supported the use of rituximab, even as first approach, although its real efficacy is still a matter of debate mainly due to the short literature material available.

\section{Funding}

This article has been published without the support of sponsors.

\section{Conflicts of Interest}

Authors declare they have no competing financial interests concerning the topic of this article.

\section{REFERENCES}

1. Kessler CM, Knöbl P. Acquired haemophilia: an overview for clinical practice. Eur J Haematol 2015; 95 Suppl 81: 36-44; https://doi.org/10.1111/ejh.12689

2. Mulliez SM, Vantilborgh A, Devreese KM. Acquired hemophilia: a case report and review of the literature. Int J Lab Hematol 2014; 36: 398-407; https://doi.org/10.1111/ijlh.12210

3. Collins P, Macartney N, Davies R, et al. A population based, unselected, consecutive cohort of patients with acquired haemophilia A. BrJ Haematol 2004; 124: 86-90; https://doi.org/10.1046/ j.1365-2141.2003.04731.x

4. Collins PW, Hirsch S, Baglin TP, et al. Acquired hemophilia A in the United Kingdom: a 2-year national surveillance study by the United Kingdom Haemophilia Centre Doctors'Organisation. Blood 2007; 109: 1870-7; https://doi.org/10.1182/blood-2006-06-029850

5. Tay L, Duncan E, Singhal D, et al. Twelve years of experience of acquired hemophilia A: trials and tribulations in South Australia. Semin Thromb Hemost 2009; 35: 769-77; https://doi. org/10.1055/s-0029-1245109

6. Kruse-Jarres R, Kempton CL, Baudo F, et al. Acquired hemophilia A: Updated review of evidence and treatment guidance. Am J Hematol 2017; 92: 695-705; https://doi.org/10.1002/ ajh. 24777

7. Delgado J, Jimenez-Yuste V, Hernandez-Navarro F, et al. Acquired haemophilia: review and meta-analysis focused on therapy and prognostic factors. Br J Haematol 2003; 121: 21-35; https://doi.org/10.1046/j.1365-2141.2003.04162.x

8. Collins P, Baudo F, Huth-Kühne A, et al. Consensus recommendations for the diagnosis and treatment of acquired hemophilia A. BMC Res Notes 2010; 3: 161; https://doi.org/10.1186/17560500-3-161

9. Collins PW, Chalmers E, Hart D, et al.; United Kingdom Haemophilia Centre Doctors' Organization. Diagnosis and management of acquired coagulation inhibitors: a guideline from UKHCDO. Br J Haematol 2013; 162: 758-73; https://doi.org/10.1111/bjh.12463

10. Knoebl P, Marco P, Baudo F, et al. Demographic and clinical data in acquired hemophilia A: results from the European Acquired Haemophilia Registry (EACH2).JThromb Haemost 2012; 10: 622-31; https://doi.org/10.1111/j.1538-7836.2012.04654.x

11. Sallah S. Treatment of acquired haemophilia with factor eight inhibitor bypassing activity. Haemophilia 2004; 10: 169-73; https://doi.org/10.1046/j.1365-2516.2003.00856.x

12. Hay CR, Negrier C, Ludlam CA. The treatment of bleeding in acquired haemophilia with recombinant factor VIIa: a multicentre study. Thromb Haemost 1997; 78: 1463-7; https://doi. org/10.1055/s-0038-1665434

13. Summer MJ, Geldziler BD, Pedersen M, et al. Treatment of acquired haemophilia with recombinant activated FVII: a critical appraisal. Haemophilia 2007; 13: 451-61; https://doi. org/10.1111/j.1365-2516.2007.01474.x

14. Collins $P$, Baudo F, Knoebl P, et al. Immunosuppression for acquired hemophilia A: results from the European Acquired Haemophilia Registry (EACH2). Blood 2012; 120: 47-55; https://doi. org/10.1182/blood-2012-02-409185

15. Borg JY, Guillet B, Le Cam-Duchez V, et al. Outcome of acquired haemophilia in France: the prospective SACHA (Surveillance des Auto antiCorps au cours de l'Hemophilie Acquise) registry. Haemophilia 2013; 19: 564-70; https://doi.org/10.1111/hae.12138

16. Hay CR, Brown S, Collins PW, et al. The diagnosis and management of factor VIII and IX inhibitors: a guideline from the United Kingdom Haemophilia Centre Doctors Organisation. Br J Haematol 2006; 133: 591-605; https://doi.org/10.1111/j.1365-2141.2006.06087.x

17. Green D, Lechner K. A survey of 215 non-hemophilic patients with inhibitors to Factor VIII. Thromb Haemost 1981; 45: 200-3; https://doi.org/10.1055/s-0038-1650169 
18. Khodamoradi Z, Nazarinia MA, Bazdar S. Acquired Hemophilia as Initial Presentation in a Patient with Systemic Lupus Erythematosus. Curr Rheumatol Rev 2017; 13: 236-8; https:// doi.org/10.2174/1573397113666170519121952

19. Dicke C, Holstein K, Schneppenheim S, et al. Acquired hemophilia A and von Willebrand syndrome in a patient with late-onset systemic lupus erythematosus. Exp Hematol Oncol 2014; 3: 21; https://doi.org/10.1186/2162-3619-3-21

20. Seethala S, Collins NP Jr, Comerci G Jr. An Unusual Etiology for Elevation of Activated Partial Thromboplastin Time (aPTT) in SLE: Acquired Hemophilia and Lupus Anticoagulant. Case Rep Hematol 2013; 2013: 521785; https://doi.org/10.1155/2013/521785

21. Shen CY, Fu LS, Lin HK, et al. Macrohematuria as initial presentation in a girl with factor VIII and factor IX inhibitors associated with systemic lupus erythematosus. J Pediatr Hematol Oncol 2012; 34: e344-e345; https://doi.org/10.1097/MPH.0b013e3182678ec1

22. Rezaieyazdi Z, Sharifi-Doloui D, Hashemzadeh $K$, et al. Acquired haemophilia A in a woman with autoimmune hepatitis and systemic lupus erythematosus; review of literature. Blood Coagul Fibrinolysis 2012; 23: 71-4; https://doi.org/10.1097/MBC.0b013e32834c6cce

23. Porru G, Mura V, Piga M, et al. Hemarthrosis as acute presentation of acquired hemophilia in a patient with systemic lupus erythematosus: successful treatment and long-lasting remission. Clin Rheumatol 2008; 27: 1581-4; https://doi.org/10.1007/s10067-008-0993-y

24. Akahoshi M, Aizawa K, Nagano S, et al. Acquired hemophilia in a patient with systemic lupus erythematosus: a case report and literature review.Mod Rheumatol 2008; 18: 511-5; https://doi. org/10.3109/s10165-008-0084-6

25. Ishikawa T, Tsukamoto N, Suto M, et al. Acquired hemophilia A in a patient with systemic lupus erythematosus. Intern Med 2001; 40: 541-3; https://doi.org/10.2169/internalmedicine.40.541

26. Trotta F, Bajocchi G, La Corte R, et al. Long-lasting remission and successful treatment of acquired factor VIII inhibitors using cyclophosphamide in a patient with systemic lupus erythematosus. Rheumatology (Oxford) 1999; 38: 1007-9; https://doi.org/10.1093/ rheumatology/38.10.1007

27. Pirner K, Rösler W, Kalden JR, et al. Long-term remission after i.v. immunoglobulin therapy in acquired antihemophilic factor hemophilia with systemic lupus erythematosus. $Z$ Rheumatol 1990; 49: 378-81

28. Nishino Y, Ueki K, Suto M, et al. Successful treatment of patients with rheumatic disorders and acquired factor VIII inhibitors with cyclophosphamide and prednisolone combination therapy: two case reports.JInt Med Res 2001;29: 432-6; https://doi.org/10.1177/147323000102900508

29. Sebastian A, Misterska-Skóra M, Podolak-Dawidziak M, et al. Pregnancy exacerbates complications of acquired hemophilia in a patient with systemic lupus erythematosus. Postepy Dermatol Alergol 2015; 32: 235-8; https://doi.org/10.5114/pdia.2014.40964

30. Onishi S, Hojo N, Sakai I, et al. Rupture of the gallbladder in a patient with acquired factor VIII inhibitors and systemic lupus erythematosus. Intern Med 2004; 43: 1073-7; https://doi. org/10.2169/internalmedicine.43.1073

31. Lafferty TE, Smith JB, Schuster SJ, et al. Treatment of acquired factor VIII inhibitor using intravenous immunoglobulin in two patients with systemic lupus erythematosus. Arthritis Rheum 1997; 40: 775-8; https://doi.org/10.1002/art.1780400426

32. Schulman S, Langevitz P, Livneh A, et al. Cyclosporine therapy for acquired factor VIII inhibitor in a patient with systemic lupus erythematosus. Thromb Haemost 1996; 76: 344-6; https://doi. org/10.1055/s-0038-1650581

33. Ghozlani I, Mounach A, Ghazi M, et al. Targeting Acquired Hemophilia A with Rheumatoid Arthritis by a Rituximab Shot: A Case Report and Review of the Literature. Am J Case Rep 2018; 19: 582-8; https://doi.org/10.12659/AJCR.908854

34. Hashimoto A, Takafuta T, Kido M, et al. Successful management of recurrent bleeding with tocilizumab in an acquired hemophilia A patient with rheumatoid arthritis. Rinsho Ketsueki 2017; 58: 738-42

35. Drobiecki A, Pasiarski M, Hus I, et al. Acquired hemophilia in the patient suffering from rheumatoid arthritis: case report. Blood Coagul Fibrinolysis 2013; 24: 874-80; https://doi. org/10.1097/MBC.0b013e3283646635

36. Banse $\mathrm{C}$, Benhamou $\mathrm{Y}$, Lequerré $\mathrm{T}$, et al. Acquired hemophilia possibly induced by etanercept in a patient with rheumatoid arthritis. Joint Bone Spine 2015; 82:200-2; https://doi.org/10.1016/j. jbspin.2014.12.003

37. Arthanari S, Ahmad H, Nisar M. Fatal acquired hemophilia A in a patient with rheumatoid arthritis treated with adalimumab.J Clin Rheumatol 2012; 18: 50-1; https://doi.org/10.1097/ RHU.0b013e31823ee3cd 
38. Patel RS, Harman KE, Nichols C, et al. Acquired haemophilia heralded by bleeding into the oral mucosa in a patient with bullous pemphigoid, rheumatoid arthritis, and vitiligo. Postgrad Med J 2006; 82: e3; https://doi.org/10.1136/pgmj.2005.036483

39. Oliveira B, Arkfeld DG, Weitz IC, et al. Successful rituximab therapy of acquired factor VIII inhibitor in a patient with rheumatoid arthritis. J Clin Rheumatol 2007; 13: 89-91; https://doi. org/10.1097/01.rhu.0000260656.05638.f7

40. Sato T, Hagiwara K, Chikazoe J, et al. A case of acquired hemophilia caused by factor VIII inhibitor with rheumatoid arthritis, successfully treated with immunosuppressive treatment and recombinant activated factor VII. Mod Rheumatol 2004; 14: 320-2; https://doi.org/10.3109/ s10165-004-0317-2

41. Jones SM, Dippy JE, Gaywood IC. Acquired haemophilia presenting with a haemarthrosis in a patient with rheumatoid arthritis and carcinoma of the lung. Br J Rheumatol 1994; 33: 992; https://doi.org/10.1093/rheumatology/33.10.992

42. Struillou L, Fiks-Sigaud M, Barrier J, et al. Acquired haemophilia and rheumatoid arthritis: success of immunoglobulin therapy. J Intern Med 1993; 233: 304-5; https://doi. org/10.1111/j.1365-2796.1993.tb00994.x

43. Ruiz-Calderón AJ, Carrasco F, Duro R, et al. Acquired factor VIII inhibitor in a patient with rheumatoid arthritis. Sangre (Barc) 1993; 38: 403-5

44. Carmassi F, Giannarelli C, De Giorgi A, et al. Combined factor VIII and IX inhibitors in a non-haemophilic patient: successful treatment with immunosuppressive drugs. Haemophilia 2007; 13: 106-7; https://doi.org/10.1111/j.1365-2516.2006.01352.x

45. Vintimilla M, Joseph A, Ranganathan P. Acquired factor VIII inhibitor in Sjögren's syndrome. Arthritis Care Res (Hoboken) 2010; 62: 1047-50; https://doi.org/10.1002/acr.20147

46. Dannhäuser D, Casonato A, Pietrogrande F, et al. Acquired factor VIII:C inhibitor in a patient with Sjögren's syndrome: successful treatment with steroid and immunosuppressive therapy. Acta Haematol 1994; 91: 73-6; https://doi.org/10.1159/000204257

47. Dachman AF, Margolis H, Aboulafia E. Does Sjögren's syndrome predispose surgical patients to acquired hemophilia? J Am Osteopath Assoc 1995; 95: 115-8, 121

48. Braunert L, Bruegel M, Pfrepper C, et al. Rituximab in the treatment of acquired haemophilia A in a patient with polymyalgia rheumatica. Hamostaseologie 2010; 30 Suppl 1: S40-S43

49. Gallant M, Lories R, Verbanck J. Polymyalgia rheumatica/arteritis temporalis and acquired factor VIII inhibitor. Clin Rheumatol 2008; 27 Suppl 1: S19-S21; https://doi.org/10.1007/ s10067-007-0817-5

50. De Langhe E, Lenaerts J, Dierickx D, et al. Acquired haemophilia A in a patient with systemic sclerosis treated with autologous haematopoietic stem cell transplantation. Rheumatology (Oxford) 2015; 54: 196-7; https://doi.org/10.1093/rheumatology/keu402

51. Yamaguchi T, Itoh $M, U$ mezawa $Y$, et al. Acquired hemophilia $A$ and fulminant diabetes mellitus possibly caused by adalimumab in a patient with psoriatic arthritis. J Dermatol 2017; 44: e3-e4; https://doi.org/10.1111/1346-8138.13468

52. Smolen JS, Landewé R, Bijlsma J, et al. EULAR recommendations for the management of rheumatoid arthritis with synthetic and biological disease-modifying antirheumatic drugs: 2016 update.Ann Rheum Dis 2017; 76: 960-77; https://doi.org/10.1136/annrheumdis-2016-210715

53. Ghozlani I, Mounach A, Ghazi M, et al. Targeting Acquired Hemophilia A with Rheumatoid Arthritis by a Rituximab Shot: A Case Report and Review of the Literature. Am J Case Rep 2018; 19: 582-8; https://doi.org/10.12659/AJCR.908854

54. D'Arena G, Grandone E, Di Minno MN, et al. Acquired hemophilia a successfully treated with rituximab. Mediterr J Hematol Infect Dis 2015; 7: e2015024; https://doi.org/10.4084/ mjhid.2015.024

55. Mumoli N, Giorgi-Pierfranceschi M, Ferretti A, et al. Acquired Hemophilia Treated Using Low-Dose of Rituximab.J Am Geriatr Soc 2016; 64: 1744-5; https://doi.org/10.1111/jgs.14188

56. Rossi B, Blanche P, Roussel-Robert V, et al. Rituximab as first-line therapy for acquired haemophilia A: a single-centre 10-year experience. Haemophilia 2016; 22: e338-e341; https:// doi.org/10.1111/hae.12973

57. Bonfanti $\mathrm{C}$, Crestani $\mathrm{S}$, Frattini $\mathrm{F}$, et al. Role of rituximab in the treatment of postpartum acquired haemophilia A: a systematic review of the literature. Blood Transfus 2015; 13:396-400

58. Franchini M, Mannucci PM. Inhibitor eradication with rituximab in haemophilia: where do we stand? Br J Haematol 2014; 165: 600-8; https://doi.org/10.1111/bjh.12829

59. Cretel E, Jean R, Chiche L, et al. Successful treatment with rituximab in an elderly patient with acquired factor VIII inhibitor. Geriatr Gerontol Int 2009; 9: 197-9; https://doi.org/10.1111/ j.1447-0594.2008.00491.x 
60. Machado P, Raya JM, Martín T, et al. Successful response to rituximab in two cases of acquired haemophilia refractory to standard-therapy. Int J Hematol 2008; 87: 545-9; https://doi. org/10.1007/s12185-008-0077-4

61. Wermke M, von Bonin M, Gehrisch S, et al. Successful eradication of acquired factorVIII-inhibitor using single low-dose rituximab. Haematologica 2010; 95: 521-2; https://doi. org/10.3324/haematol.2009.017749

62. Yao Q, Zhu X, Liu Y, et al. Low-dose rituximab in the treatment of acquired haemophilia. Hematology 2014; 19: 483-6; https://doi.org/10.1179/1607845414Y.0000000152

63. Xu Y, Zhang X, Zhao Y, et al. Successful treatment of a patient with acquired haemophilia A with a combination of a low-dose rituximab and recombinant human FVIIa. Haemophilia 2013; 19: e95-e96; https://doi.org/10.1111/hae.12070 